Supporting information for Macromolecules

\title{
Phase Controllable Hyaluronic Acid Hydrogel with Iron(III) Ion- Catechol Induced Dual Cross-Linking by Utilizing the Gap of Gelation Kinetics
}

Jeongwook Lee, ${ }^{\dagger}$ Kyeol Chang,, Sunhye Kim, ${ }^{\dagger}$ Vikas Gite, ${ }^{\|}$Hoeil Chung, ${ }^{\#}$ and Daewon Sohn* ${ }^{* \dagger}$

\footnotetext{
${ }^{\dagger}$ Research Institute for Convergence of Basic Science, ${ }^{\# A n a l y t i c a l ~ S p e c t r o s c o p y ~ L a b, ~ D e p a r t m e n t ~ o f ~ C h e m i s t r y, ~}$ Hanyang University, Seoul 133-791, Republic of Korea

"Department of Polymer Chemistry, School of Chemical Sciences, North Maharashtra University, Jalgaon 425001, Maharashtra, India
} 


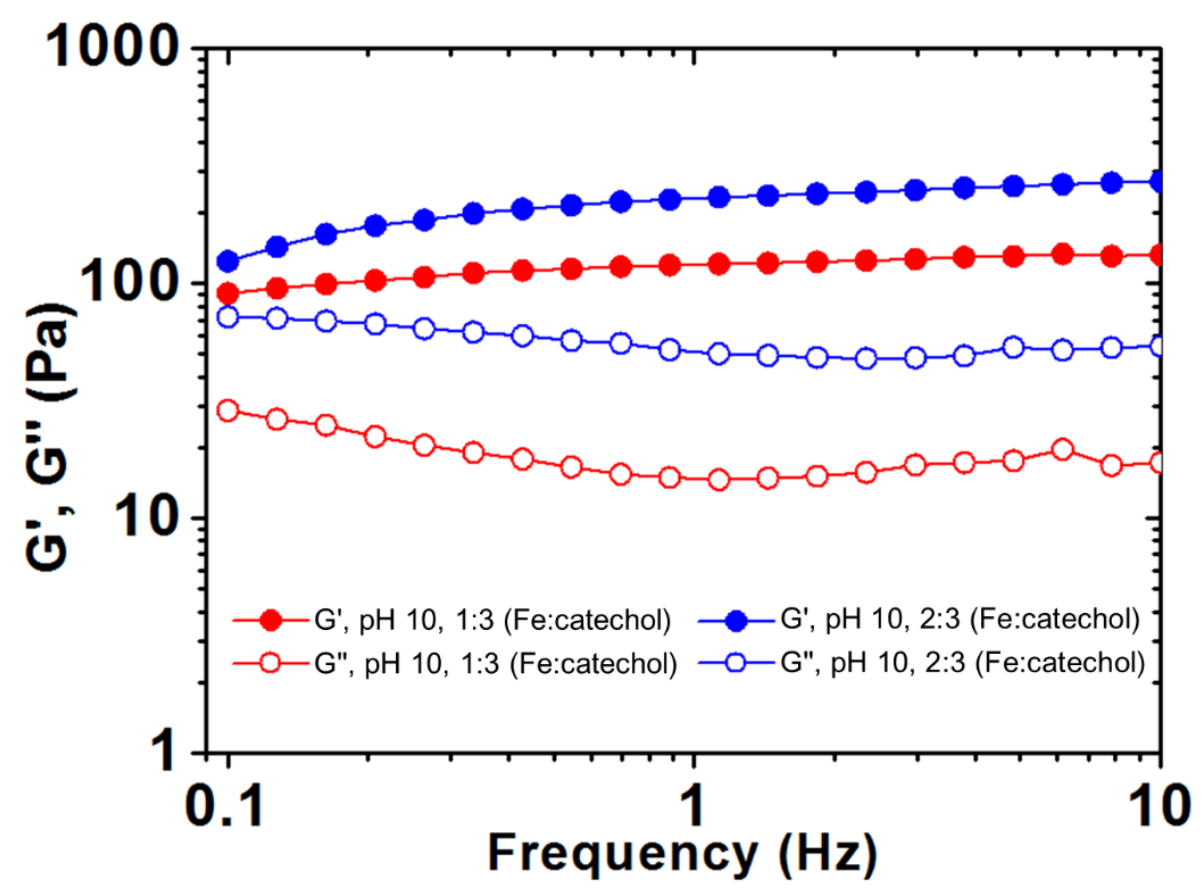

Figure S1. Rheological properties of HA-CA hydrogels formed at pH 10.0 after curing by changing $\mathrm{Fe}^{3+}$ :catechol molar ratio

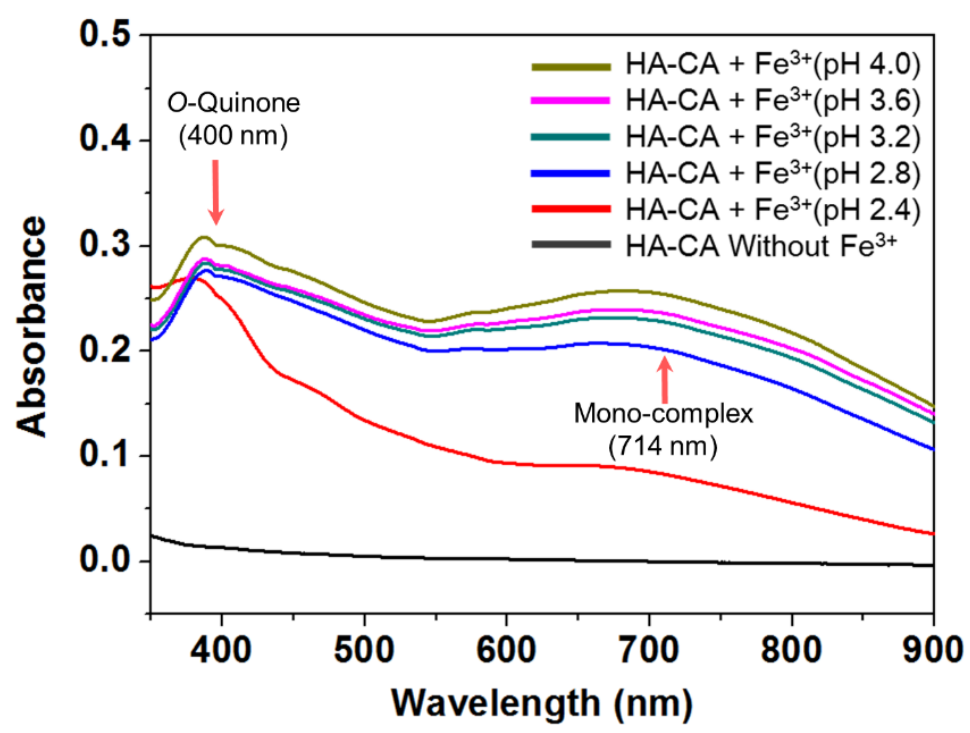

Figure S2. UV-Vis spectra of mixtures of HA-CA and $\mathrm{Fe}^{3+}$ with $\mathrm{pH}$ control from 2.4 to 4.0. 

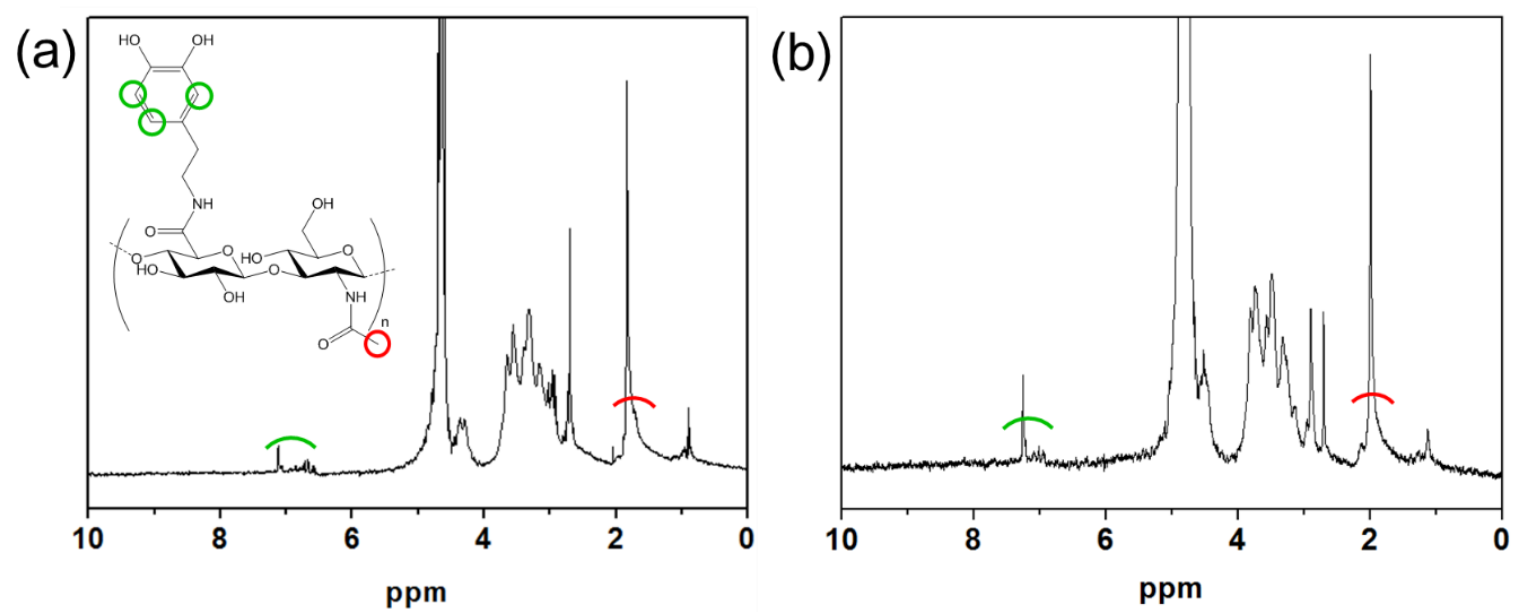

Figure S3. ${ }^{1} \mathrm{H}$ NMR spectra of (a) $19 \%$ substituted and (b) $27 \%$ substituted HA-CA synthesized by means of EDC/HOBt coupling.

Table S1. Gelation times versus catechol modification ratio of HA-CA
Catechol modified Curing time for
ratio in $\mathrm{HA}-\mathrm{CA}(\%) \quad$ gelation (min) 